\title{
Injections of an Opioid Antagonist Into the Locus Coeruleus and Periaqueductal Gray But Not the Amygdala Precipitates Morphine Withdrawal in the 7-Day-Old Rat
}

\author{
KATHY L. JONES ${ }^{1}$ AND GORDON A. BARR ${ }^{1,2 *}$ \\ ${ }^{1}$ Biopsychology Doctoral Program, City University of New York, Psychology Department, \\ Hunter College, City University of New York, New York \\ ${ }^{2}$ Department of Developmental Psychobiology, New York State Psychiatric Institute, Columbia University \\ College of Physicians and Surgeons, New York, New York
}

KEYWORDS opiate; dependence; brain sites; ontogeny

\begin{abstract}
Opiate withdrawal behaviors in the infant differ from those of the adult. The neural circuitry underlying opioid withdrawal in the adult rat is well defined and includes the locus coeruleus (LC) and periaqueductal gray (PAG), with a minor role of the amygdala. Because the different behaviors that constitute the infant syndrome may be mediated by different neural circuits, we tested the hypothesis that these three sites are involved in opiate withdrawal. Pups were injected with morphine from day 1-6 after birth (b.i.d.) and on the morning of the seventh day. Withdrawal was then elicited by local injection of the opioid antagonist methylnaloxonium into the LC, PAG, or amygdala. Withdrawal signs were precipitated in a dose-dependent manner following injection into the LC or PAG, but not the amygdala. The withdrawal behaviors elicited from the LC and PAG included both the same and different behaviors. The results support the hypothesis that the neural circuitry mediating opiate withdrawal behaviors is similar in infant and adult animals, but the behaviors expressed are age-specific. Synapse 39: 139-151, 2001. ๑ 2001 Wiley-Liss, Inc.
\end{abstract}

\section{INTRODUCTION}

The chronic administration of opiate drugs induces a state of physical dependence in both humans and animals. The physical component of morphine dependence is characterized by specific behavioral and vegetative signs following the cessation of opiate administration (spontaneous withdrawal) or by administration of an opiate antagonist (precipitated withdrawal). The adult rodent has been the model most commonly used to investigate the anatomical substrates that mediate the diverse symptoms of the opiate withdrawal syndrome. Opiate drugs act principally on the central nervous system (CNS) (Bell and Adler, 1988), and the anatomical sites involved in the opiate withdrawal syndrome are widely represented within the CNS (Kimes and London, 1989; Hayward et al., 1990; Maldonado et al., 1992). These sites have been identified with a variety of technologies, all of which support the hypothesis that no single brain structure is entirely responsible for the classic signs of opiate withdrawal in the adult rat. Studies involving intracerebral injections of opiate antagonists into specific brain structures in the adult rat support the hypothesis that a network of multiple sites mediates opiate withdrawal within the CNS. Areas found to be highly sensitive to the opiate antagonist naloxone were the medial hypothalamus, the periaqueductal gray of the midbrain (PAG)/4th ventricle area, amygdala, medial thalamus, and globus pallidus (Wei et al., 1973; Tremblay and Charton, 1981). Naloxone is lipophilic; therefore, recent studies have utilized methylnaloxonium, a hydrophilic opiate antagonist, to reduce the rapid diffusion of the drug (Stinus et al., 1990; Maldonado et al., 1992). Methylnaloxonium binds competitively to opiate receptor sites, is ten times less potent than naloxone, but remains at the site of injection much longer than naloxone (Schroeder et al., 1990). The LC has been shown to be the most sensitive site for methylnaloxonium-precipitated withdrawal, including jumping, rearing, and locomotor activity (Maldonado et al., 1992; but also see Christie et al., 1997).

Contract grant sponsor: NIH; Contract grant numbers: DA06600, DA00325, DA05632.

*Correspondence to: Gordon A. Barr, Ph.D., Department of Psychology, Hunter College, 695 Park Avenue, New York, New York, 10021.

E-mail: gbarr@shiva.hunter.cuny.edu

Received 22 March 2000; Accepted 25 May 2000 
Injections of methylnaloxonium into the PAG also increased rearing and locomotor activity. The least sensitive structures that still elicited methylnaloxoniumprecipitated withdrawal were the amygdala, nucleus accumbens, and medial thalamus.

Collectively, these studies have mapped out the anatomical substrates involved in the opiate withdrawal syndrome. Whereas much progress has been made in our understanding of how the behavioral, anatomical, and molecular components function together to produce the opiate withdrawal syndrome in the adult rat, virtually nothing is known regarding the interactions of these mechanisms in the developing animal. This lack of information is due in part to the fact that the behavioral signs associated with this syndrome in the developing animal are distinct and different from the classic signs of opiate withdrawal observed in the adult animal. Until very recently there has been no detailed behavioral description that profiles the opiate withdrawal syndrome in the developing animal. Three labs have now described the maturation of the opiate withdrawal syndrome as it is manifested in the fetal, neonatal, and adolescent animal. At each level of development, precipitated withdrawal is evidenced by a distinct and consistent behavioral syndrome, but the nature of that syndrome changes with age. The classical withdrawal signs associated with adult opiate withdrawal do not appear until puberty (Jones and Barr, 1995; Windh et al., 1995; Thornton and Smith, 1997; Thornton et al., 1997; Jones and Barr, 2000). These data provide a model detailing the physical component of withdrawal at each different stage of development and thereby set the stage for the study of the anatomical substrates that mediate the opiate withdrawal syndrome in the developing animal.

Our working model is that withdrawal is an ensemble of behaviors mediated by multiple neural circuits organized in a hierarchical manner. It is likely that some circuits are mature early and that others develop later. Given the immaturity of the autonomic nervous system at 7 days of age, and given the lack of autonomic signs in withdrawal at that age, the circuits cannot be the same in infancy and adulthood. Whether or not higher level sites, which integrate a variety of withdrawal signs in the adult, have similar functions in the infant as in the adult is not known. Thus, we tested the hypothesis that higher-order, integrative systems (e.g., PAG, LC, amygdala) are mature early but that the "effector" systems mature later. The goal of this study is therefore to determine if the changing face of opiate withdrawal during development is mediated by similar or different neural sites as in the adult. We precipitated opiate withdrawal in morphine-dependent 7-day-old rat pups by injecting methylnaloxonium into one of three different brain structures, the amygdala, LC, or PAG, and measured the resultant changes in behavior.

\section{MATERIALS AND METHODS Subjects}

The subjects were offspring of Long-Evans hooded rats mated in our laboratory. The parent rats were housed in plastic tubs in a colony room maintained at $22-24^{\circ} \mathrm{C}$ with a 12 -h light-dark photocycle with light onset at 7 AM. Cages were checked twice daily at approximately $10 \mathrm{AM}$ and $6 \mathrm{PM}$. Pups found at either time were termed 0 days of age. After parturition, litters were culled to eight pups without regard for the ratio of males to females.

\section{Procedure Induction of morphine dependence}

Animals were injected with morphine sulfate (10 $\mathrm{mg} / \mathrm{kg}$ ip) twice daily (10 AM and $6 \mathrm{PM}$ ), from the first to the seventh day of life. Controls included saline-injected pups. The last injection was on the morning of the seventh day. The order of the treatments was assigned randomly with the exception that a maximum of six litters was used per condition. A total of 12 litters were used per brain site, six litters for each treatment group.

\section{Cannula implantation}

On the evening of the sixth day the animals were transported from the animal facility to our labs in plastic tubs with bedding and placed in an observation chamber and maintained at approximately $33^{\circ} \mathrm{C}$. One rat was then fully anesthetized with Metafane and placed in a stereotaxic device adapted for infant animals (Heller et al., 1979). The field was prepped and the skin and muscle layers reflected. A burr hole was made in the skull and the cannula placed to the required depth and anchored with dental cement. The coordinates for amygdala placements were AP, -2.0 , $\mathrm{ML},-3.6$, and DV, -2.4 . Locus coeruleus coordinates were $\mathrm{AP}-2.8, \mathrm{ML},-.8$, and $\mathrm{DV},-1.7$. PAG coordinates were $\mathrm{AP},-4.2, \mathrm{ML},-.5$, and $\mathrm{D}-2.3$. The incision was closed with cyanoacrylate cement. Cannula guides were permanently kept open with wire stylets that were removed for intracerebral injections. Following surgery pups were kept together in a warm, moist incubator $\left(34^{\circ} \mathrm{C}\right)$ overnight without the dam. Prior to behavioral testing on day 7, pups were fed milk (halfand-half) from a plastic pipette to help maintain hydration. These methods have been described in detail previously (Barr, 1991).

\section{Induction of morphine withdrawal}

On the afternoon of the seventh day, one pup was weighed, rectal temperature recorded, and injected with saline or methylnaloxonium (generously supplied by Boehringer-Ingelheim, Elmsford, NY) through the cannula. The following doses were injected in order to precipitate withdrawal: $30,100,300,1,000 \mathrm{ng} / \mathrm{injec}-$ 
TABLE I. Behavioral definitions

\begin{tabular}{|c|c|}
\hline Behavior & Definitions \\
\hline Burrow & $\begin{array}{l}\text { Sliding the body under the shavings of the } \\
\text { observation chamber }\end{array}$ \\
\hline Chewing & Repeated mouth movements \\
\hline Head moves & Lateral and rotary motions of the head \\
\hline Moving paws & $\begin{array}{l}\text { Continuous movement of the hindpaws without } \\
\text { walking }\end{array}$ \\
\hline Quiet & Sedated appearance with no movement \\
\hline Rolling & Turning the body over at least one full rotation \\
\hline Separation & Without contact with any littermates \\
\hline Stretching & $\begin{array}{l}\text { Extension or dorsal flexion of the trunk causing an } \\
\text { apparent lengthening of the body }\end{array}$ \\
\hline Together & Bodily contact with one or more littermates \\
\hline Vocalization & Audible sounds emitted from the pup \\
\hline Walking & Taking more than one step forward \\
\hline Wall climbing & $\begin{array}{l}\text { Placing at least two forepaws on the wall of the } \\
\text { observation chamber }\end{array}$ \\
\hline
\end{tabular}

From Jones and Barr, 1995.

tion. A solution of $0.20 \mu \mathrm{l}$ was injected over $70 \mathrm{sec}$ through a injector cannula (Plastic Products, Roanoke, VA; 315I, 33 ga. $200 \mu \mathrm{m}$ ) and associated tubing inserted into the guide cannula. The injector extended 1 $\mathrm{mm}$ beyond the ventral edge of the guide. The external end of the tubing was connected to a $5 \mu$ l syringe (Hamilton, Reno, NV) that was filled with distilled water. A small air bubble was left between the drug and water to prevent dilution and to serve as a calibration for the injection volume. After injection the cannula was left in place for an additional minute before being removed.

\section{Behavioral testing}

Immediately following the injection the pup was placed in an observation chamber with the remainder of the litter. The pup was then observed for a period of $20 \mathrm{~min}$ and behaviors recorded every $15 \mathrm{sec}$ on a checklist (see Table I). The checklist was developed in previous experiments by observing and recording behaviors displayed by morphine-treated pups after systemic injection of naltrexone (Jones and Barr, 2000). When the observation period ended, rectal temperature was rerecorded and the pup was anesthetized and placed back into the litter. This was done in order to quiet the pup, prevent interference with the next observational pup, and to maintain constant litter size. The second pup was then injected and tested in this manner.

\section{Histological verification}

After completion of withdrawal testing, all the animals were deeply anesthetized with sodium pentobarbital and perfused with $10 \%$ formalin. The brain was removed from the skull, cut on a cryostat at $-20^{\circ} \mathrm{C}$, and stained with cresyl violet. Representative sections showing the site of injection were then compared to standard stereotaxic plates (Paxinos and Watson, 1986). Histological analysis was conducted without knowledge of the behavioral results.
TABLE II. Analyses of variance for withdrawal behaviors at each brain site

\begin{tabular}{|c|c|c|}
\hline \multicolumn{3}{|l|}{ Chewing } \\
\hline PAG & ND & \\
\hline $\mathrm{LC}$ & $(4,36)=3.54$ & $<0.01$ \\
\hline Amygdala & $(4,40)=1.00$ & NS \\
\hline \multicolumn{3}{|l|}{ Head moves } \\
\hline PAG & $(4,44)=2.36$ & $<0.06^{*}$ \\
\hline $\mathrm{LC}$ & $(4,36)=7.55$ & $<0.001$ \\
\hline Amygdala & $(4,40)=1.98$ & NS \\
\hline \multicolumn{3}{|l|}{ Paw moves } \\
\hline PAG & $(4,44)=5.30$ & $<0.001$ \\
\hline $\mathrm{LC}$ & $(4,36)=11.47$ & $<0.0001$ \\
\hline Amygdala & $(4,40)=1.97$ & NS \\
\hline \multicolumn{3}{|l|}{ Quiet } \\
\hline PAG & $(4,44)=21.26$ & $<0.0001$ \\
\hline $\mathrm{LC}$ & $(4,36)=48.62$ & $<0.0001$ \\
\hline Amygdala & $(4,40)=1.08$ & NS \\
\hline \multicolumn{3}{|l|}{ Rolling } \\
\hline PAG & $(4,44)=5.63$ & $<0.001$ \\
\hline $\mathrm{LC}$ & $(4,36)=48.62$ & NS \\
\hline Amygdala & $(4,40)=1.13$ & NS \\
\hline \multicolumn{3}{|l|}{ Separation } \\
\hline PAG & $(4,44)=1.45$ & NS \\
\hline $\mathrm{LC}$ & $(4,36)=0.44$ & NS \\
\hline Amygdala & $(4,40)=0.60$ & NS \\
\hline \multicolumn{3}{|l|}{ Together } \\
\hline PAG & $(4,44)=0.89$ & NS \\
\hline $\mathrm{LC}$ & $(4,36)=0.84$ & NS \\
\hline Amygdala & $(4,40)=0.51$ & NS \\
\hline \multicolumn{3}{|l|}{ Vocalization } \\
\hline PAG & ND & - \\
\hline $\mathrm{LC}$ & $(4,36)=6.03$ & $<0.001$ \\
\hline Amygdala & $(4,40)=1.00$ & NS \\
\hline \multicolumn{3}{|l|}{ Walking } \\
\hline PAG & $(4,44)=2.64$ & $<0.05$ \\
\hline $\mathrm{LC}$ & $(4,36)=1.81$ & NS \\
\hline Amygdala & $(4,40)=1.44$ & NS \\
\hline \multicolumn{3}{|l|}{ Wall climbs } \\
\hline PAG & $(4,44)=3.57$ & $<0.01$ \\
\hline $\mathrm{LC}$ & $(4,36)=2.75$ & $<0.05$ \\
\hline Amygdala & $(4,40)=1.36$ & NS \\
\hline
\end{tabular}

$\mathrm{ND}=$ not determined; NS = not significant.

*Trend only.

\section{Statistics}

A factorial analysis of variance (ANOVA) was conducted for each behavior in each different brain site. Since chewing and vocalizations were not detected during precipitated withdrawal in the PAG, analyses were not performed for these behaviors in the PAG. The 20-min observation period was divided into five different time periods, each consisting of $4 \mathrm{~min}$. Behaviors were summed in each time period, which was treated as a within-subjects variable. All doses were injected within a single litter and the drug dose effect was treated as a within-subjects variable. The different brain sites and chronic treatment groups served as between-subjects variables.

\section{RESULTS}

Microinjection of naltrexone in morphine-dependent animals produced clear signs of withdrawal following injection of the PAG or LC, but not the amygdala. Results of the time interval were not unique and for simplicity the data presented here are collapsed over the $20 \mathrm{~min}$. There were two possible effects: chronic treatment effects (morphine vs. saline-treated groups) and interaction effects between naltrexone dose and 
TABLE III. Behaviors unaltered by precipitated withdrawal at each brain site

\begin{tabular}{|c|c|c|c|c|c|}
\hline \multicolumn{6}{|c|}{ Dose of methylnaloxonium (ng/injection) } \\
\hline Amygdala & 0 & 30 & 100 & 300 & 1000 \\
\hline Chewing & 0.0 & 0.0 & $0.0 \pm 0.0$ & 0.0 & 0.0 \\
\hline Quiet & $12.0 \pm 0.6$ & $10.5 \pm 0.6$ & $11.6 \pm 0.6$ & $11.0 \pm 0.7$ & $11.8 \pm 0.7$ \\
\hline Paw moves & $0.5 \pm 0.1$ & $30 \pm 0.4$ & $1.9 \pm 0.3$ & $1.5 \pm 0.3$ & $1.6 \pm 0.3$ \\
\hline Rolling & 0.0 & $0.0 \pm 0.0$ & 0.0 & 0.0 & $0.0 \pm 0.0$ \\
\hline Separated & $1.4 \pm 0.7$ & $0.1 \pm 0.1$ & $0.3 \pm 0.3$ & $2.4 \pm 0.9$ & $2.6 \pm 1.0$ \\
\hline Stretch & 0.0 & 0.0 & 0.0 & 0.0 & 0.0 \\
\hline Together & $12.5 \pm 0.9$ & $14.4 \pm 0.5$ & $14.0 \pm 0.6$ & $11.8 \pm 1.0$ & $11.6 \pm 1.0$ \\
\hline Vocalizing & 0.0 & 0.0 & 0.0 & 0.0 & 0.0 \\
\hline Wall Climb & 0.0 & $0.0 \pm 0.0$ & 0.0 & $0.10 \pm .1$ & $0.0 \pm 0.0$ \\
\hline Walk & $0.1 \pm 0.1$ & $0.7 \pm 0.2$ & $0.3 \pm 0.1$ & $0.8 \pm 0.3$ & $0.5 \pm 0.2$ \\
\hline \multicolumn{6}{|l|}{ PAG } \\
\hline Separated & $2.0 \pm 0.8$ & $4.5 \pm 0.9$ & $2.1 \pm 0.5$ & $5.1 \pm 1.1$ & $2.0 \pm 0.6$ \\
\hline Stretch & 0.0 & 0.0 & 0.0 & $0.1 \pm 0.1$ & $0.03 \pm 0.03$ \\
\hline Together & $12.0 \pm 1.1$ & $10.3 \pm 1.0$ & $12.5 \pm 0.8$ & $9.33 \pm 1.1$ & $10.1 \pm 1.2$ \\
\hline \multicolumn{6}{|l|}{ LC } \\
\hline Rolling & 0.0 & $0.6 \pm 0.2$ & $0.2 \pm 0.1$ & $0.6 \pm 0.2$ & $0.6 \pm 0.2$ \\
\hline Separated & $1.4 \pm 0.6$ & $1.7 \pm 0.4$ & $2.3 \pm 0.7$ & $1.8 \pm 0.5$ & $1.7 \pm 0.6$ \\
\hline Stretch & 0.0 & 0.0 & 0.0 & 0.0 & 0.0 \\
\hline Together & $11.1 \pm 0.8$ & $10.8 \pm 0.7$ & $10.3 \pm 0.8$ & $9.72 \pm 0.8$ & $11.9 \pm 0.8$ \\
\hline
\end{tabular}

Cell entries are means \pm 1 SEM of occurrences in morphine-treated animals. " 0.0 " indicates the behavior did not occur; " $0.0 \pm 0.0$ " indicates the behavior occurred but averaged less than 0.05 occurrences.

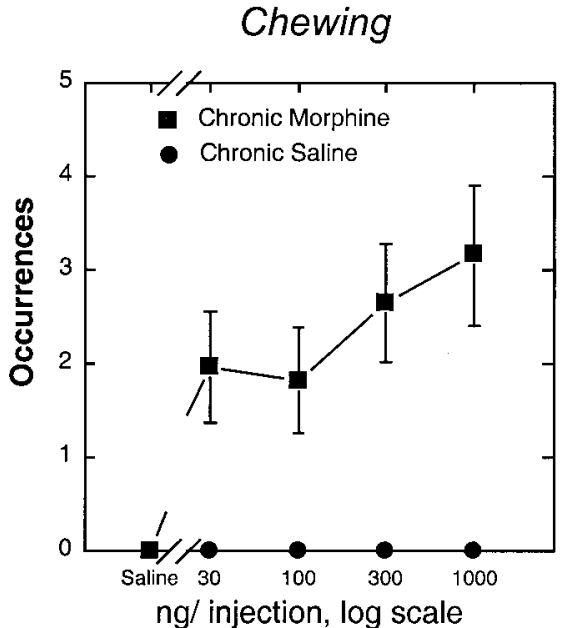

$\mathrm{ng} /$ injection, log scale

\section{Moving Paws}

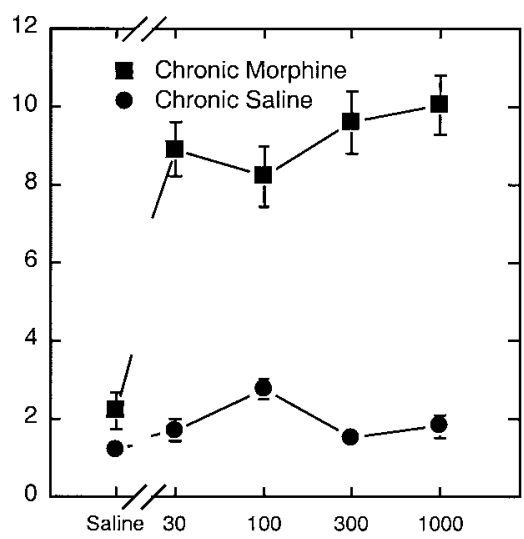

$\mathrm{ng} /$ injection, log scale

\section{Quiet}

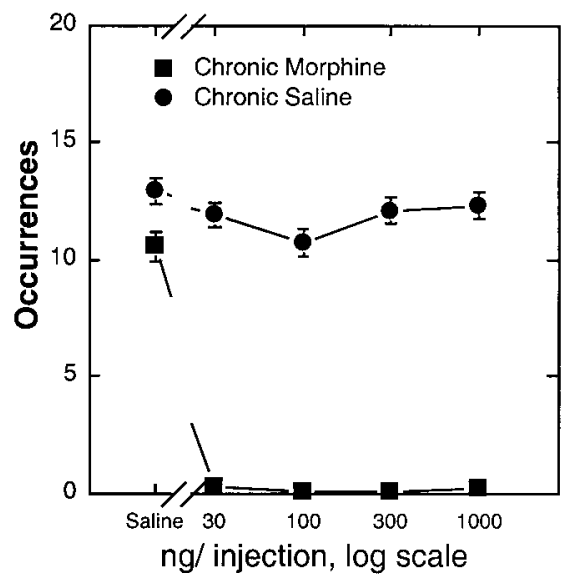

Vocalizations

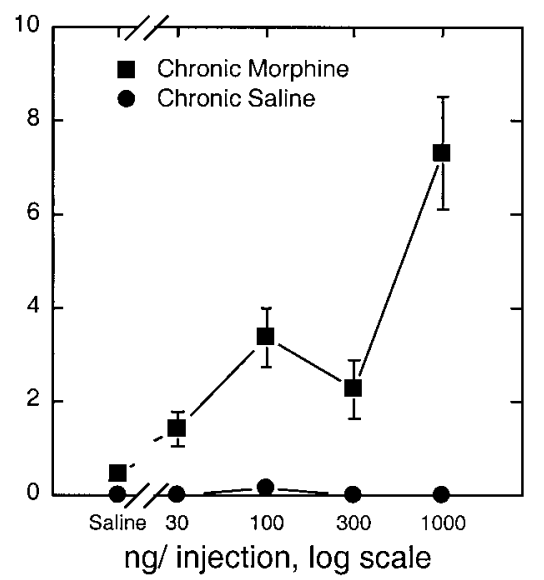

Fig. 1. Mean number ( \pm 1 SEM) of occurrences of significantly elicited behaviors occurring following injection of methylnaloxonium into the LC. Chronic treatment groups included morphine $(10 \mathrm{mg} / \mathrm{kg})$ and saline-injected litters. There were a total of five morphine-treated litters and a total of six salineinjected litters. A total of five pups were tested per litter. 

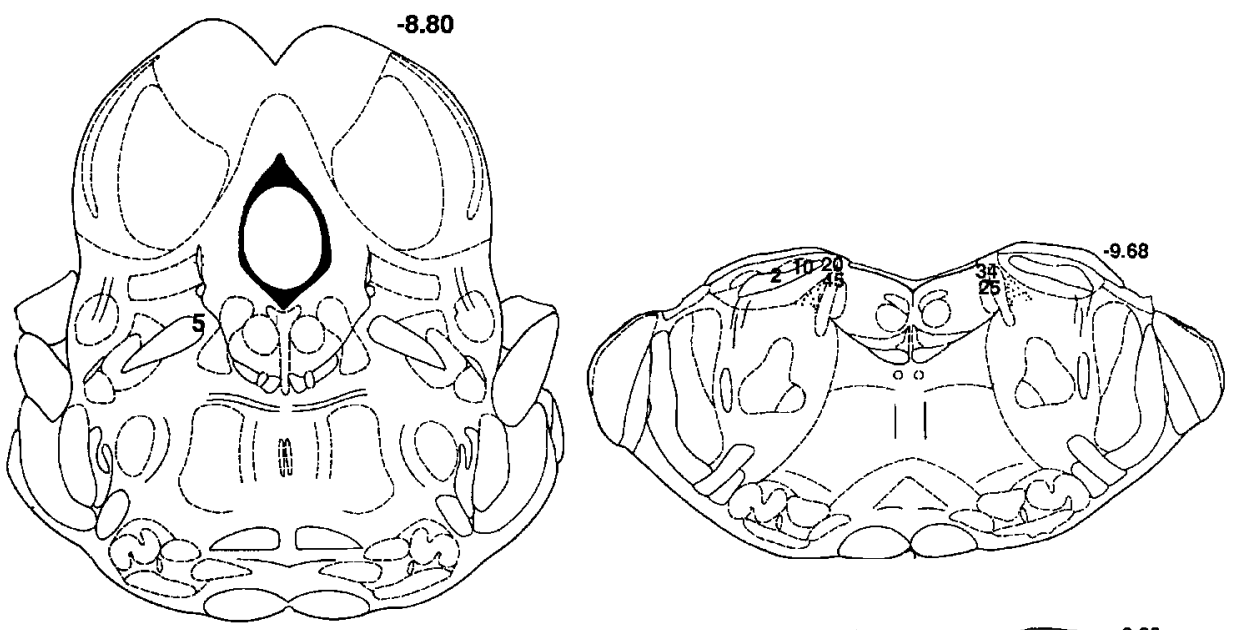

Fig. 2. Representative coronal sections of morphine-dependent rats showing the total number of occurrences for the behavior "vocalization" at each injection site following injection of methylnaloxonium into the LC $(n=17)$.
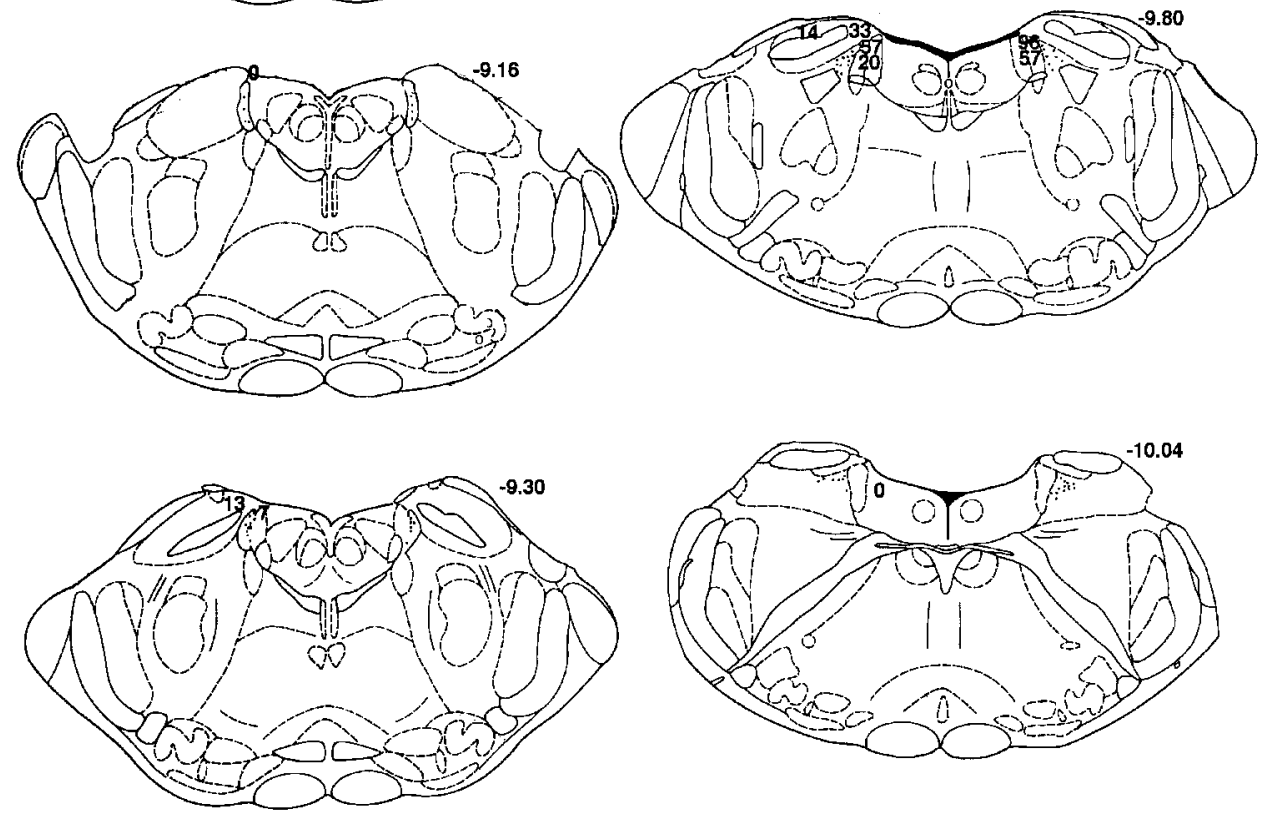

chronic treatment. The statistical analyses are detailed in Table II, and behaviors that were not significantly altered at each brain sites are given in Table III.

\section{Behavior}

\section{Locus coeruleus}

The administration of methylnaloxonium into the locus coeruleus of morphine-dependent animals produced a severe withdrawal syndrome and significantly elicited the following signs of withdrawal: head movements, mouthing, hindpaw movements, vocalizations, wall climbing, and less time spent quiet as compared to control animals (Fig. 1). Other signs such as rolling, stretching, and walking which are normally observed in the morphine-dependent neonate following systemic injections were not significantly increased. Animals receiving the highest dose of methylnaloxonium $(1,000$ ng) engaged in continuous mouthing movements and displayed a loud and clearly audible vocalization throughout the observation period.

\section{Histology}

Figure 2 depicts the number of occurrences of vocalizations plotted as a function of cannula placement. Figure 3 similarly depicts paw moves as a function of injection site. Animals with placements within the LC showed the most behaviors, whereas those with the sites of injection outside but in the proximity of the LC exhibited fewer withdrawal behaviors. This can be seen for example in sections AP $-8.8,-9.16$, and in particular -9.68 and -9.80 . Although these plots are independent of dose, the dose-response curves were flat for moving paws, and thus the effectiveness of the placements was not a function of different doses.

\section{Behavior}

\section{Periaqueductal gray matter}

The following signs were significantly elicited following administration of methylnaloxonium into the ven- 

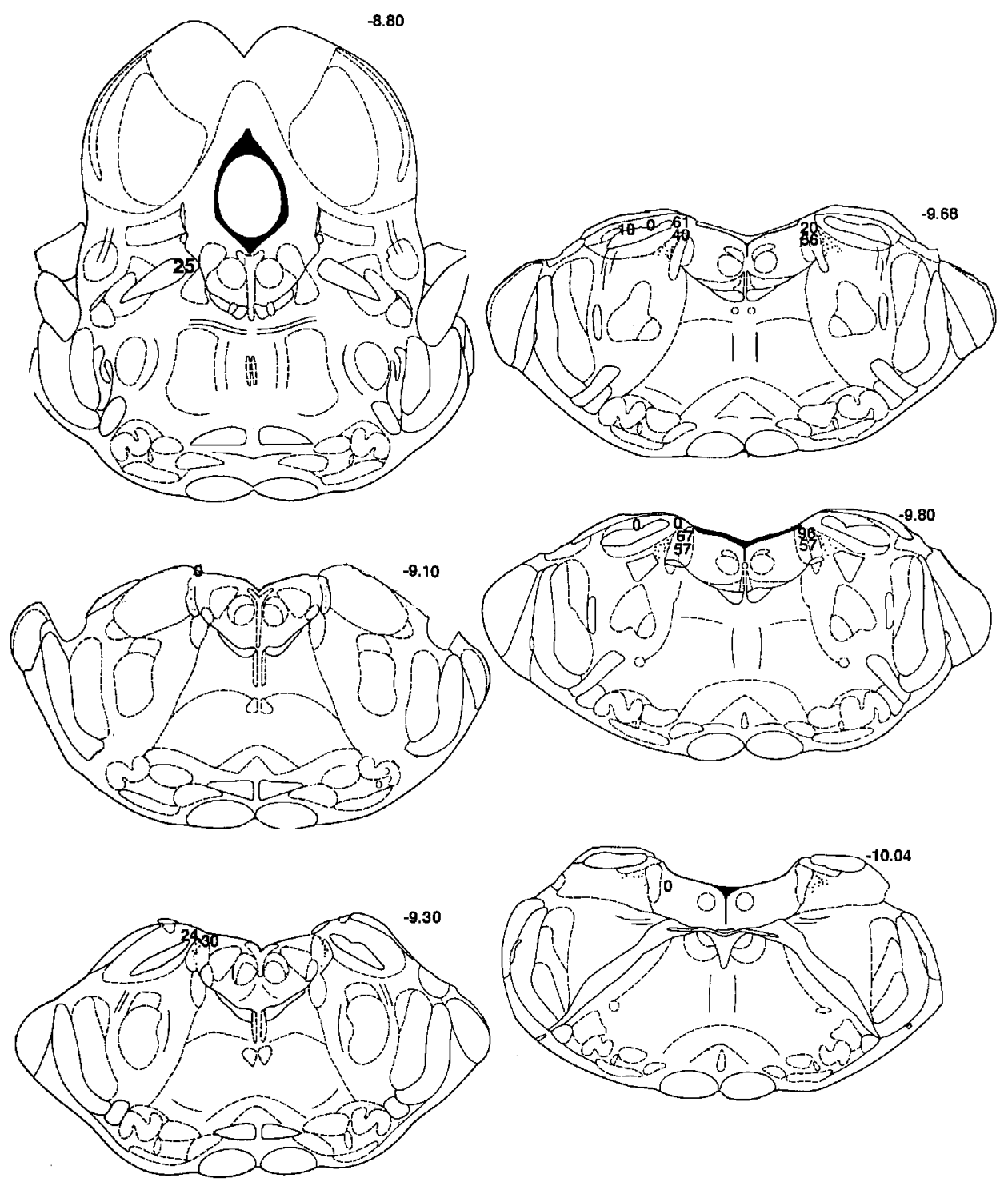

Fig. 3. Representative coronal sections of morphine-dependent rats showing the total number of occurrences for the behavior "paw moves" at each injection site following methylnaloxonium into the LC $(n=17)$

tral PAG of morphine-dependent animals: head movements, hindpaw movements, rolling, walking, wall climbing, and less time spent quiet as compared to control animals (Fig. 4). Paw movement and rolling were the most sensitive signs, showing a significant presence after administration of the lowest dose of methylnaloxonium (30 ng).

\section{Histology}

Figure 5 depicts the number of occurrences of paw moves plotted as a function of cannula placement. Figure 6 similarly depicts rolling as a function of injection site. Almost all sites were within the lateral or ventrolateral PAG and were effective. There were no obvious differences in effectiveness as a function of site within these subdivisions of the PAG, nor were there any noted rostral-to-caudal differences.

\section{Amygdala}

Methylnaloxonium injections into the amygdala failed to elicit any physical signs of withdrawal in morphinedependent rat pups. There were no observable behavioral differences between the two treatment groups.

\section{Histology}

Figures 7 and 8 demonstrate the placements of cannula in the amygdala for morphine-treated pups (Fig. 7) and saline-treated controls (Fig. 8). Because there were no significant behavioral effects of amygdaloid stimulation, only the placements are provided. There were no obvious differences between the loci of cannula in the control and treated pups.

\section{DISCUSSION}

These data show that the administration of the hydrophilic opiate antagonist methylnaloxonium into the 

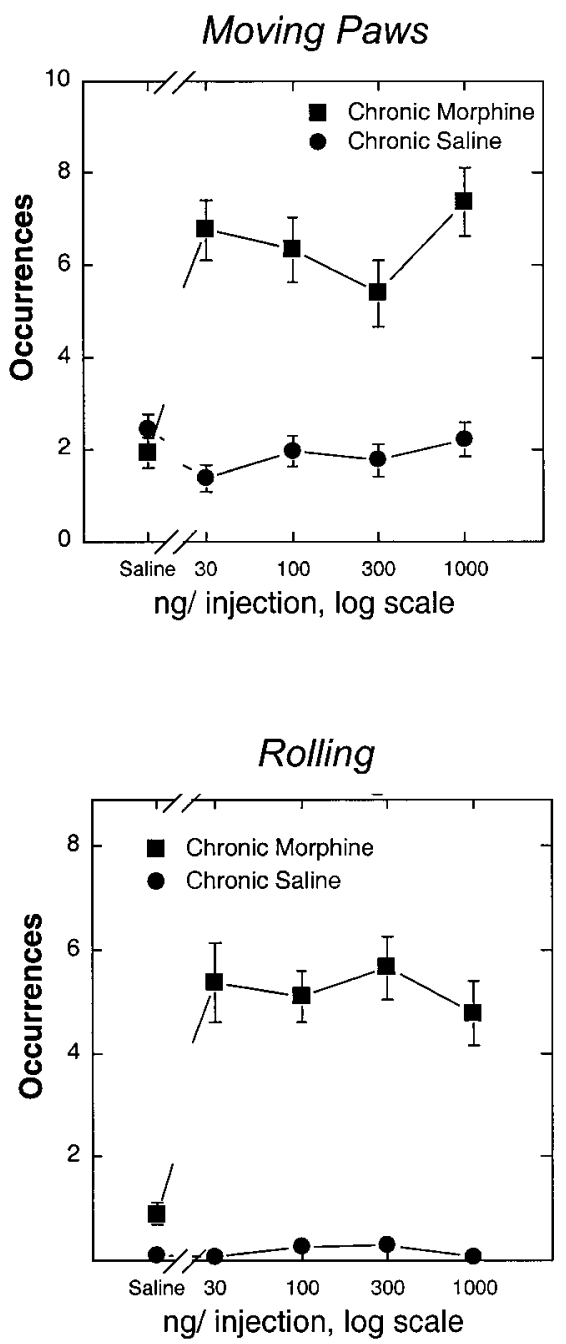

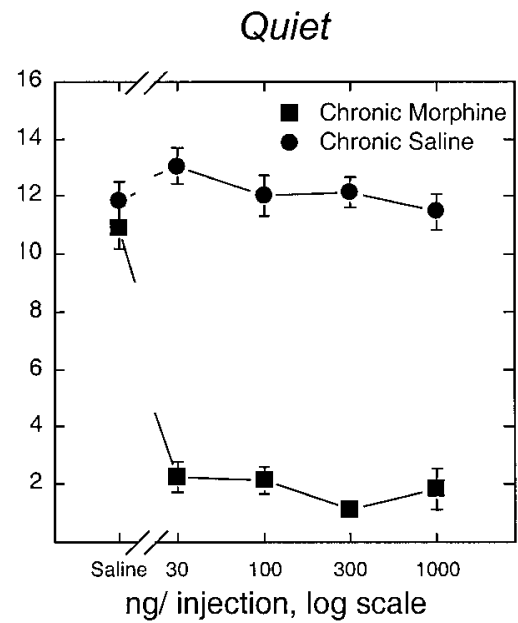

Walk

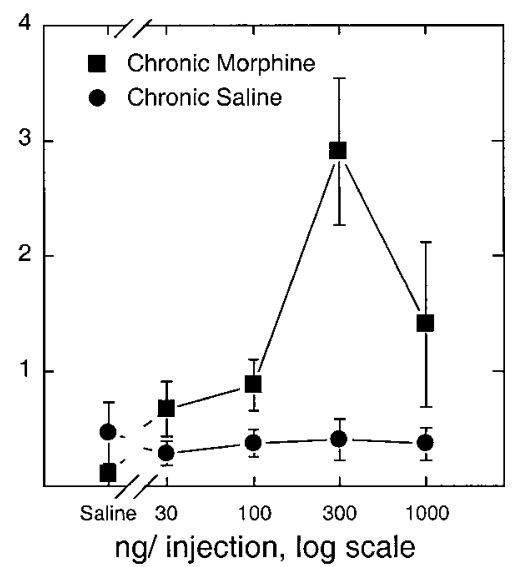

Fig. 4. Mean number $( \pm 1$ SEM $)$ of occurrences for behaviors significantly elicited following methylnaloxonium injection into the PAG. Chronic treatment groups included morphine-exposed and saline-treated animals. There were six morphine-treated litters and six saline-treated litters. Five pups were tested per litter. periaqueductal gray or locus coeruleus, but not the amygdala, elicit clear signs of opiate withdrawal. Withdrawal induced after administration of methylnaloxonium into the LC and PAG of morphine-dependent 7-day-old rats was similar to that reported after systemic administration of naltrexone in the 7-day-old rat (Jones and Barr, 1995) but there were differences between the behaviors elicited by PAG and LC stimulation. Antagonist injection to the PAG elicited intense motor signs, such as wall climbing, rolling, walking, and less time spent quiet. Injection of the LC elicited similar gross motor signs such as wall climbing, head movements, paw movements, and less time quiet, but only weakly elicited rolling and walking. The most notable difference between the two sites was the continuous mouthing movement and the loud and clearly audible vocalizations that were "chirp-like" in nature, observed following administration of methylnaloxonium into the LC of morphine-dependent animals. These behaviors were not observed following methylnaloxonium injection into the PAG of morphine-dependent animals, nor were they reported following periph- eral injections (Jones and Barr, 1995; Windh et al., 1995; Thornton and Smith, 1997; Thornton et al., 1997).

Although it is difficult to precisely define the area of stimulation following chemical stimulation (Barr, 1991), there are data from prior studies in this lab to suggest that the stimulation was limited to the area targeted. First, in a study of the effects of drugs on feeding in the infant, we stimulated the paraventricular region of the hypothalamus with various drugs. We directly injected into the third ventricle to control for spread of drug from the injection site into the ventricular system. We found that the dose-response curve was shifted 10 -fold to the right following intraventricular injection, suggesting that drug did not spread to the ventricular system (Capuano et al., 1992). Second, injections of the $\mu$ opioid antagonist CTOP unilaterally into the PAG blocked stress-induced analgesia in pups, but only ipsilateral to the injection site, not contralateral to it. Thus, drug can be localized to one side of this midline structure. Data from these experiments suggest that injections of small volumes of drug produce 


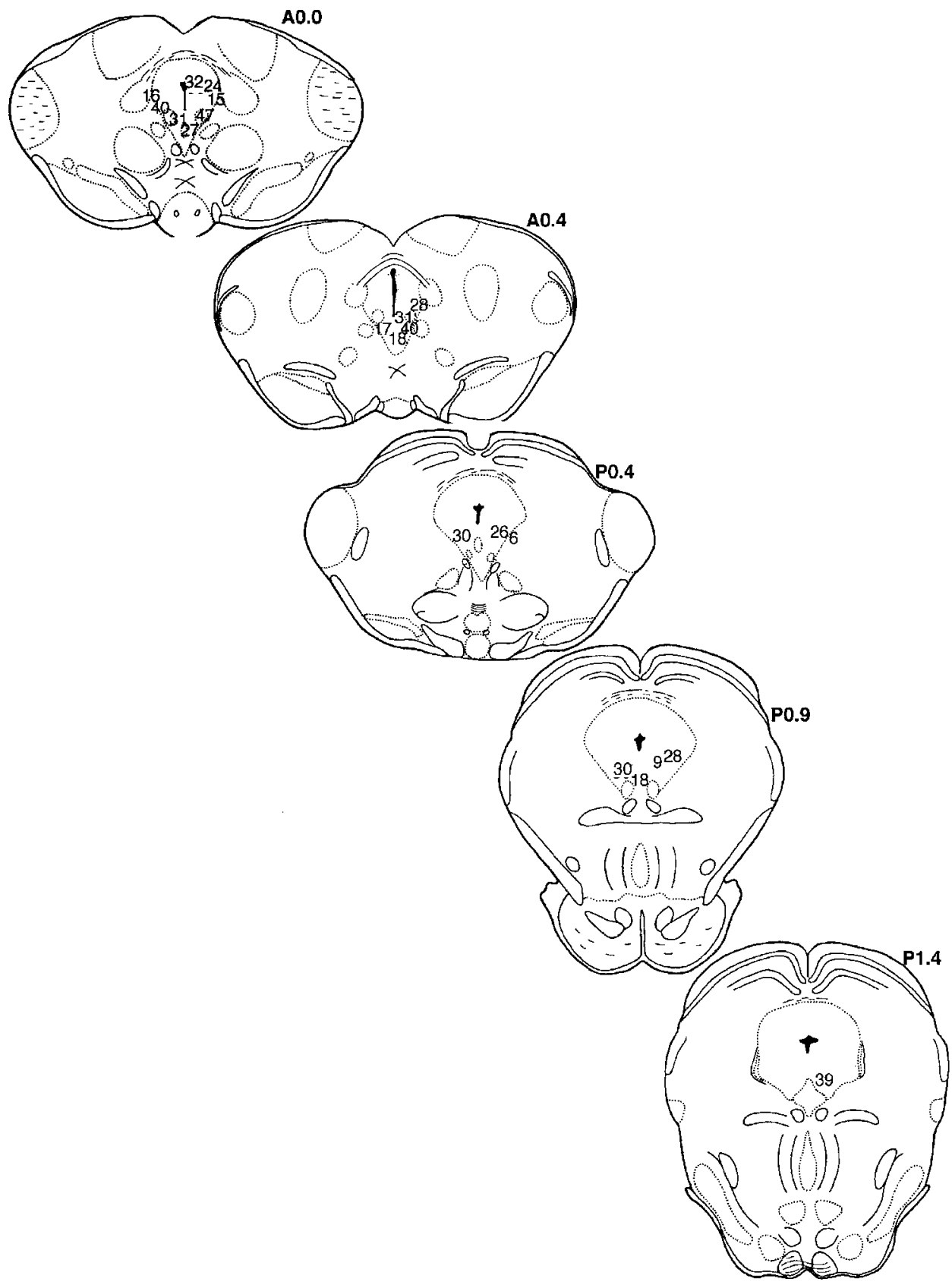

Fig. 5. Representative coronal sections of morphine-dependent animals showing the total number of occurrences of the behavior "moving paws" at each injection site following methylnaloxonium injection into the PAG $(n=21)$. their effects at the site of injection and likely do not spread either into the ventricular system or to adjacent brain sites. Third, the use of the hydrophilic form of naloxone further reduces the likelihood of significant spread. Finally, that we obtained different results from the amygdala than from the PAG and LC (which themselves differed somewhat) argues for a relatively restricted site of action. This latter point is particularly important since it has been argued that the results of methylnaloxonium injected into the LC could be due to spread to the PAG (Christie et al., 1997). However, unique behaviors such as "chirping" and mouthing were elicited from the LC but not PAG, suggesting that if there were spread of antagonist, it was not to the PAG.

\section{Locus coeruleus}

In the adult rat, as in the infant, the most sensitive site for methylnaloxonium-precipitated withdrawal is the LC (Maldonado et al., 1992; Maldonado, 1997). Signs such as jumping, rearing, teeth-chattering, chewing, and locomotor activity were particularly frequent after methylnaloxonium injections into the adult LC (Maldonado et al., 1992). The LC represents the largest cluster of noradrenergic neurons in the brain and contains a high density of opioid receptors, partic- 
Fig. 6. Representative coronal sections of morphine animals showing the total number of occurrences for the behavior "rolling" at each injection site following methylnaloxonium injections into the PAG $(n=21)$.

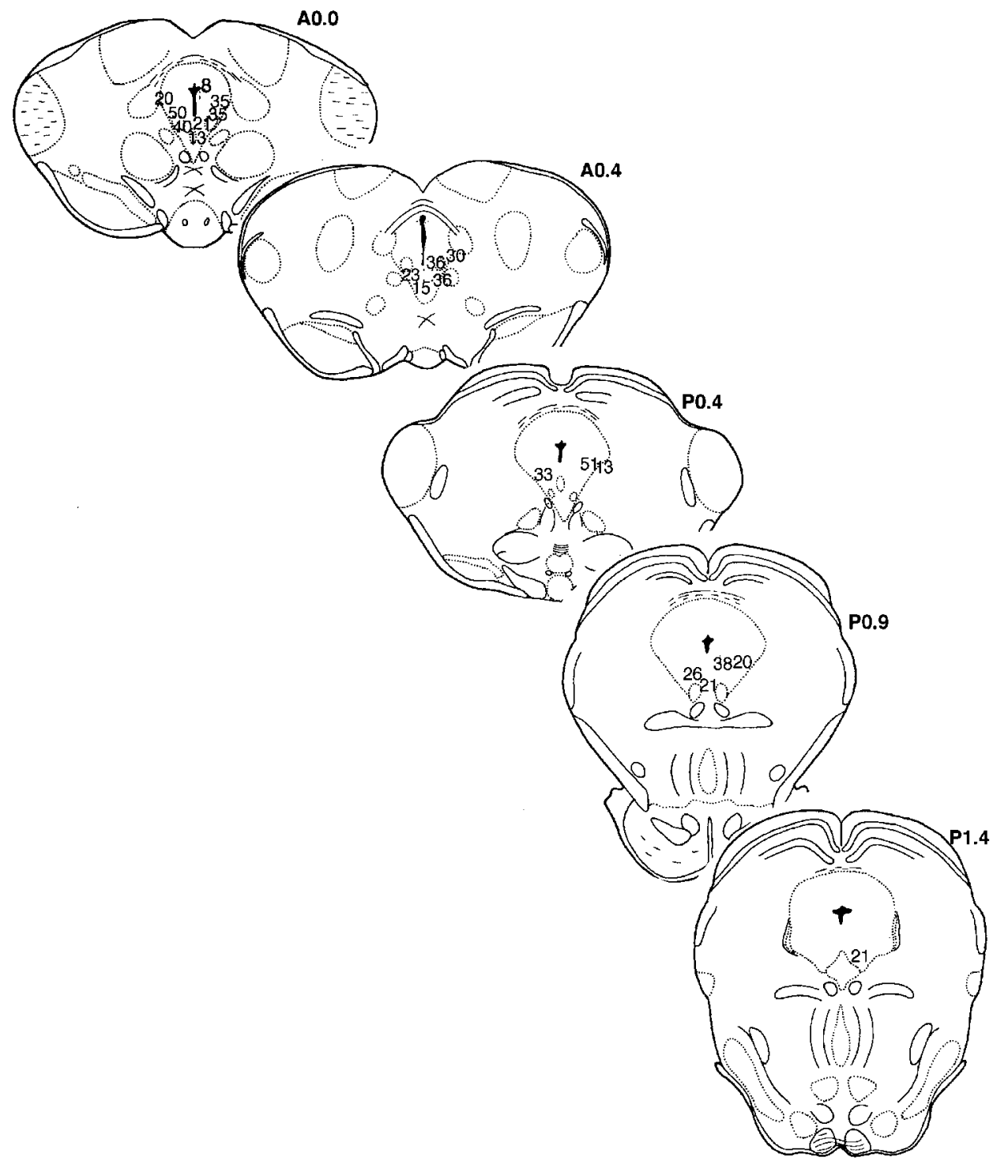

ularly of the $\mu$ type. Hyperactivity in the LC has been hypothesized to mediate the expression of some components of physical morphine withdrawal (Maldonado and Koob, 1993). However, the importance of the LC in opiate withdrawal has recently been questioned (Christie et al., 1997) and a series of recent studies has shown that the dorsal noradrenergic projection arising from the LC probably has a minimal role in withdrawal (Britton et al., 1984; Chieng and Christie, 1995; Caille et al., 1999; Delfs et al., 2000).

With the exception of the present study, there are no available data addressing the possible role of the LC in the development of morphine dependence in the neonatal animal. What we do know is that $\mu$ opiate receptors can be detected during gestation in the CNS (Kornblum et al., 1987) and relatively high levels of $\mu$ opiate receptors are present in the LC (Quirion et al., 1983). However, although LC neurons in neonates have little or no spontaneous activity, they are sensitive to both noxious and nonnoxious sensory stimuli and antidromic activation of the LC from stimulation of the cortex can be detected as early as embryonic day 18 (Nakamura and Sakaguchi, 1990). Regardless of the exact role that the LC plays in withdrawal, the data presented here for the infant are consistent with those in the adult using similar techniques. This argues for developmental continuity in the mechanisms underlying withdrawal in the adult and infant animals.

\section{Periaqueductal gray}

The administration of methylnaloxonium into the PAG also elicited a severe withdrawal syndrome in the neonatal rat. This finding parallels studies in the adult rat where methylnaloxonium injection into the PAG precipitates a strong withdrawal syndrome characterized by behaviors such as teeth-chattering, chewing, jumping, rearing, and hyperactivity. Rearing and hyperactivity were particularly elevated (Maldonado et 

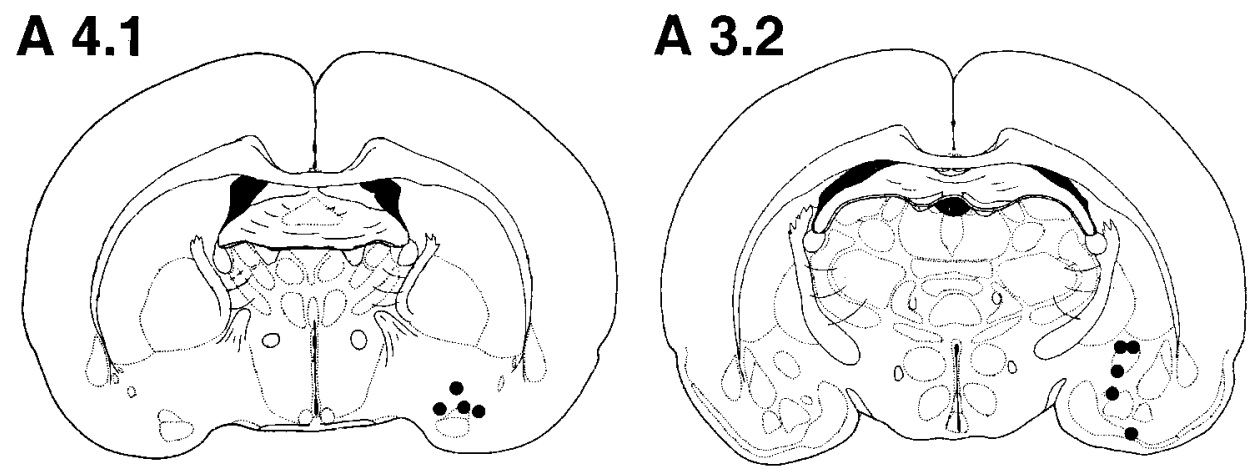

A 3.8

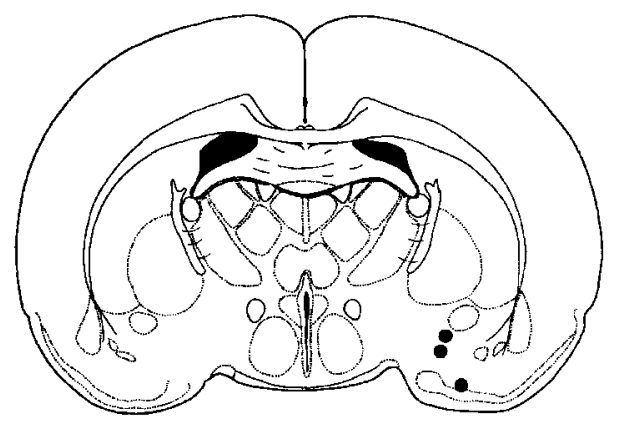

A 2.6

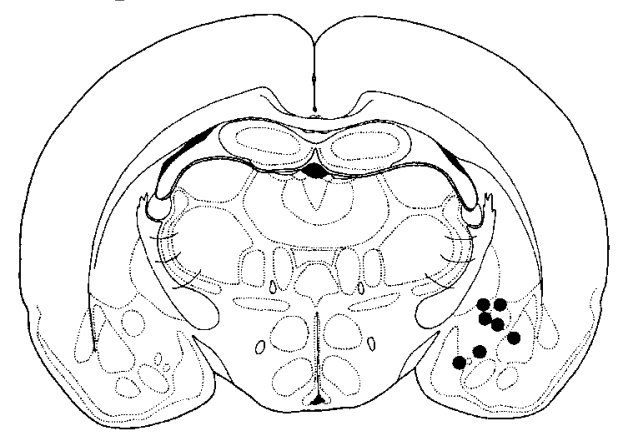

A 3.5

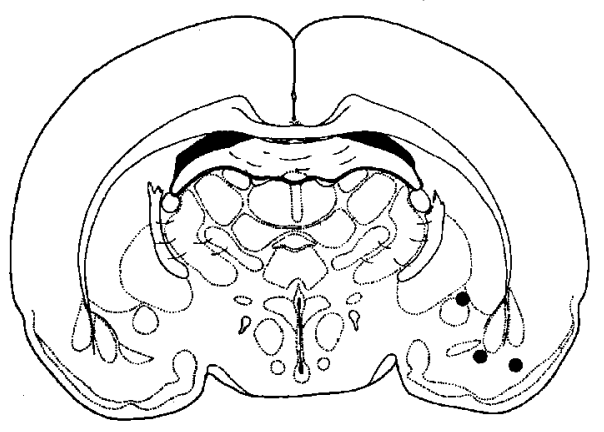

A 2.3

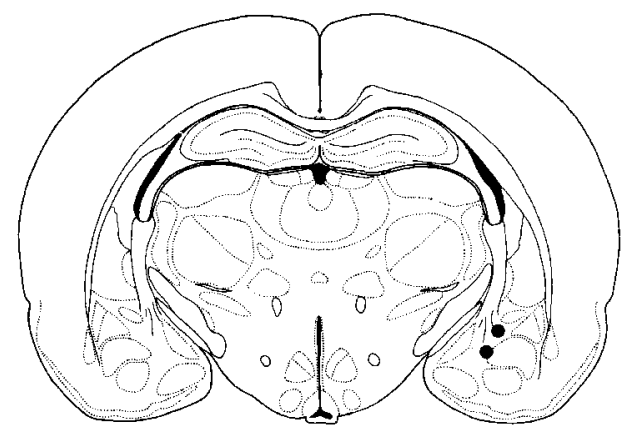

Fig. 7. Representative coronal sections of morphine-dependent animals following injection of methylnaloxonium into the amygdala $(n=24)$.

al., 1992). The general importance of the PAG in the development of opiate dependence and the expression of physical withdrawal in the adult rat has been previously supported in the past, first by the presence of a strong withdrawal syndrome following administration of opiate antagonists (naloxone and levallorphan) into the PAG (Laschka et al., 1976) and by the severe physical dependence observed after chronic administration of enkephalin analogs (Wei, 1981) and morphine (Bozarth and Wise, 1984) into this region. More recently, metabolic activity has been shown to be significantly enhanced (Kimes et al., 1990) and c-fos-like immunoreactivity in neurons of the ventrolateral PAG significantly increased during naloxone-precipitated withdrawal (Chieng et al., 1995). The PAG has also been shown to be involved in other opiate-mediated functions, notably analgesia (Sharpe et al., 1974). Although the administration of methylnaloxonium into the PAG elicits a severe withdrawal syndrome (Maldonado et al., 1992), it is not very sensitive to the meth- ylnaloxonium-induced aversive effects of opiate abstinence (Koob et al., 1989; Stinus et al., 1990). For example, local injections of methylnaloxonium into the PAG do not elicit a disruption in food operant responding in the adult rat (Koob et al., 1989) and fail to elicit place aversions (Stinus et al., 1990). Although autoradiographic studies have indicated that opiate receptors are present at significant densities in the PAG at birth (Leslie et al., 1982), with the exception of the present study there are no available data addressing the possible involvement of the PAG in the neonatal opiate withdrawal syndrome. Based on the results of the present study it seems likely that, as in the adult rat, the PAG is critically involved in the development of physical dependence and in the expression of physical withdrawal to morphine in the neonatal rat.

\section{Amygdala}

In the present study there were no behavioral changes following stimulation of the amygdala. Al- 

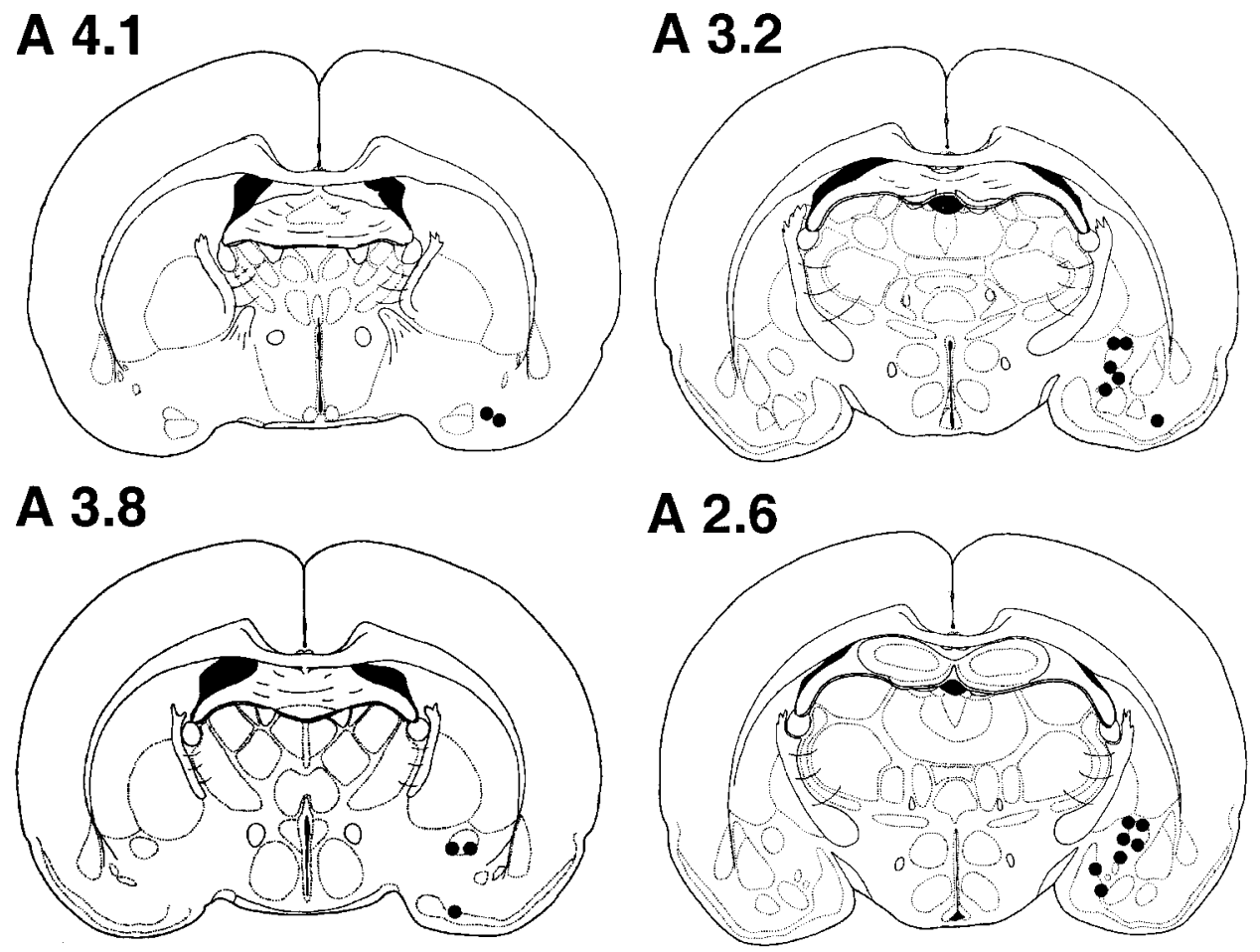

A 3.5

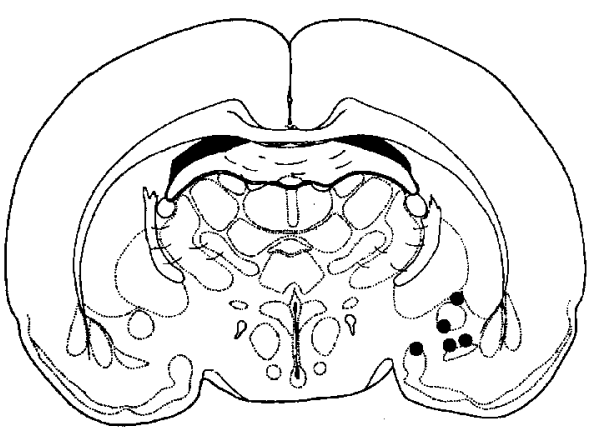

A 2.3

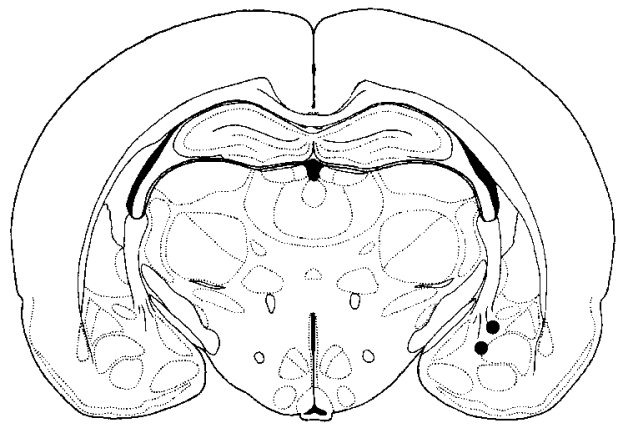

Fig. 8. Representative sections of saline-dependent animals following injection of methylnaloxonium into the amygdala $(n=24)$.

though physical signs of withdrawal from the amygdala in the adult are substantially milder than the PAG or LC, they do occur in the adult rat. Whereas earlier studies have reported a significant withdrawal syndrome, especially an increase in jumping behavior, following injection of naloxone into the amygdala of the adult (Tremblay and Charton, 1981), more recent studies injecting methylnaloxonium into the amygdala induced only a very mild withdrawal in which jumping, wet-dog shakes, and other major signs of abstinence were absent even when the antagonist was administered at the highest dose (1,000 ng) (Maldonado et al., 1992). Maldonado's group attributes this discrepancy to a greater diffusion of naloxone in the brain. However, a significant incidence of teeth-chattering and chewing was observed following antagonist injection into the amygdala of morphine-dependent animals (Maldonado et al., 1992). Chewing is also seen following antagonist injection to the LC in both the infant and adult rat, yet there was no evidence of chewing in the pup following antagonist injection to the amygdala. This suggests a differential maturation of the expression of similar behaviors. On the other hand, the amygdala has been shown to be an important anatomical site for mediating the aversive effect of opiate withdrawal. For example, low doses of methylnaloxonium into the amygdala disrupted operant responding for food and produced place aversions in morphine-dependent adult rats, but failed to elicit overt signs of withdrawal (Wei et al., 1973; Koob et al., 1989; Stinus et al., 1990). Furthermore, small lesions of the dorsomedial nuclei of the amygdala had no effect on the naltrexoneprecipitated morphine withdrawal symptoms, but they did decrease the magnitude of the conditioned place aversion produced by that withdrawal in the adult rat (Kelsey and Arnold, 1994). The poor correlation between the expression of the physical signs of opiate withdrawal and the aversive stimulus properties of 
opiate withdrawal syndrome suggests a different neuroanatomical substrate for these two processes in the adult rat. The differential development of the physical signs (Jones and Barr, 1995) and the affective aspects of withdrawal (Barr and Goodwin, 1997) are consistent with this view. Whether or not the amygdala is involved in the aversive aspects of withdrawal in the infant animal remains to be investigated.

Recently, the maturation of the physical signs of opiate withdrawal from the fetus (day 20 of gestation) through 42 days of postnatal life has been described (Jones and Barr, 1995; Windh et al., 1995; Thornton et al., 1997; Jones and Barr, 2000). At all stages of development precipitated withdrawal was evidenced by a distinct and consistent behavioral syndrome, but the nature of that syndrome changed with age. Adult-like responses, which had been studied previously, did not appear until puberty. There is no reason to assume that the same sites in the adult mediate the withdrawal syndrome in the infant. Indeed, one hypothesis for the different adult and infant constellations of withdrawal signs is that they are mediated by separate neural circuits and that the maturation of the adult withdrawal syndrome depends on the decreasing role of the neural circuits for infant abstinence and the increased involvement of neural systems involved in the adult syndrome. The alternative hypothesis is that the same neural sites mediate withdrawal throughout the life span, but the effector systems change. The results of the present study support the latter hypothesis. This does not imply that all mechanisms mediating opiate withdrawal are the same in the adult as in the infant. NMDA receptor antagonists, which ameliorate withdrawal in the adult, are ineffective either acutely or chronically in the 7-day-old pup, reducing the somatic signs of withdrawal only at 14 days of age and older (Zhu and Barr, 2000a,b).

In conclusion, it seems likely that the same neural circuitry mediates physical withdrawal at different ages, regardless of the specifics of the behaviors elicited. Our results suggest that the neural circuitry that initiates withdrawal matures early, but "downstream" effector systems (e.g., autonomic nervous system, motor systems) are develop later. The differences suggest differential maturation of certain neural mediators of withdrawal.

\section{ACKNOWLEDGMENT}

We thank Duckhyun Kim, Ph.D. for assistance with behavioral observations.

\section{REFERENCES}

Barr GA. 1991. Neuropharmaco-ontogeny: concepts and methods of study. In: Shair HN, Barr GA, Hofer MA, editors. Developmental psychobiology: new methods and changing concepts. New York: Oxford Univ Press. p 321-341.

Barr GA, Goodwin GA. 1997. Precipitated morphine withdrawal induces a conditioned aversion in the preweaning rat. Pharmacol Biochem Behav 57:779-783.
Bell J, Adler MW. 1988. Comparison of peripheral and central administration of naloxone in precipitating abstinence in morphine-dependent rats. Drug Alcohol Depend 21:189-194.

Bozarth MA, Wise RA. 1984. Anatomically distinct opiate receptor fields mediate reward and physical dependence. Science 224:516517.

Britton KT, Svensson T, Schwartz J, Bloom FE, Koob GF. 1984. Dorsal noradrenergic bundle lesions fail to alter opiate withdrawal or suppression of opiate withdrawal by clonidine. Life Sci 34:133139.

Caille S, Espejo EF, Reneric JP, Cador M, Koob GF, Stinus L. 1999. Total neurochemical lesion of noradrenergic neurons of the locus ceruleus does not alter either naloxone-precipitated or spontaneous opiate withdrawal nor does it influence ability of clonidine to reverse opiate withdrawal. J Pharmacol Exp Ther 290:881-892.

Capuano CA, Leibowitz SF, Barr GA. 1992. Pharmaco-ontogeny of hypothalamic induced feeding. Dev Brain Res 68:67-74.

Chieng B, Christie MJ. 1995. Lesions to terminals of noradrenergic locus coeruleus neurones do not inhibit opiate withdrawal behaviour in rats. Neurosci Lett 186:37-40.

Chieng B, Keay KA, Christie MJ. 1995. Increased fos-like immunoreactivity in the periaqueductal gray of anaesthetised rats during opiate withdrawal. Neurosci Lett 183:79-82.

Christie MJ, Williams JT, Osborne PB, Bellchambers CE. 1997. Where is the locus in opioid withdrawal? Trends Pharmacol Sci 18:134-140.

Delfs JM, Zhu Y, Crugan JP, Aston-Jones G. 2000. Noradrenaline in the ventral forebrain is critical for opiate withdrawal-induced aversion. Nature 403:430-434.

Hayward MD, Duman RS, Nestler EJ. 1990. Induction of the c-fos proto-oncogene during opiate withdrawal in the locus coeruleus and other regions of rat brain. Brain Res 525:256-266.

Heller A, Hutchens JO, Kirby ML, Karapas F, Fernandez C. 1979. Stereotaxic electrode placement in the neonatal rat. J Neurosci Methods 1:41-76.

Jones KL, Barr GA. 1995. Ontogeny of morphine withdrawal in the rat. Behav Neurosci 109:1189-1198.

Jones KL, Barr GA. 2000. Opiate withdrawal in the fetal rat: a behavioral profile. Pharmacol Biochem Behav 66:419-424.

Kelsey JE, Arnold SR. 1994. Lesions of the dorsomedial amygdala, but not the nucleus accumbens, reduce the aversiveness of morphine withdrawal in rats. Behav Neurosci 108:1119-1127.

Kimes AS, London ED. 1989. Glucose utilization in the rat brain during chronic morphine treatment and naloxone-precipitated morphine withdrawal. J Pharmacol Exp Ther 248:538-545.

Kimes AS, Bell JA, London ED. 1990. Clonidine attenuates increased brain glucose metabolism during naloxone-precipitated morphine withdrawal. Neuroscience 34:633-644.

Koob GF, Wall TL, Bloom FE. 1989. Nucleus accumbens as a substrate for the aversive stimulus effects of opiate withdrawal. Psychopharmacology 98:530-534.

Kornblum HI, Hurlbut DE, Leslie FM. 1987. Postnatal development of multiple opioid receptors in rat brain. Brain Res 415:21-41.

Laschka E, Teschemacher HH, Mehraein P, Herz A. 1976. Sites of action of morphine involved in the development of physical dependence in rats. II. Morphine withdrawal precipitated by application of morphine antagonists into restricted parts of the ventricular system and by microinjection into various brain areas. Psychopharmacology 46:141-147.

Leslie FM, Tso S, Hurlbut DE. 1982. Differential appearance of opiate receptor subtypes in neonatal rat brain. Life Sci 31:1393-1396.

Maldonado R. 1997. Participation of noradrenergic pathways in the expression of opiate withdrawal: biochemical and pharmacological evidence. Neurosci Biobehav Rev 21:91-104.

Maldonado R, Koob GF. 1993. Destruction of the locus coeruleus decreases physical signs of opiate withdrawal. Brain Res 605:128138 .

Maldonado R, Stinus L, Gold LH, Koob GF. 1992. Role of different brain structures in the expression of the physical morphine withdrawal syndrome. J Pharmacol Exp Ther 261:669-677.

Nakamura S, Sakaguchi T. 1990. Development and plasticity of the locus ceruleus: a review of recent physiological and pharmacological experimentation. Prog Neurobiol 34:505-526.

Paxinos G, Watson C. 1986. The rat brain in stereotaxic coordinates. San Diego: Academic Press.

Quirion R, Zajac JM, Morgat JL, Roques BP. 1983. Autoradiographic distribution of $\mathrm{mu}$ and delta opiate receptors in rat brain using highly selective ligands. Life Sci, 33(Suppl 1):227-230.

Schroeder RL, Weinger MB, Vakassiaan L, Koob GF. 1990. Methylnaloxonium diffuses out of the rat brain more slowly than naloxone after direct intracerebral injection. Neurosci Lett 121:173-177. 
Sharpe LG, Garnett JE, Cicero TJ. 1974. Analgesia and hyperactivity produced by intracranial microinjections of morphine into the periaqueductal grey matter of the rat. Behav Biol 11:303314.

Stinus L, Le Moal M, Koob GF. 1990. Nucleus accumbens and amygdala are possible substrates for the aversive stimulus effects of opiate withdrawal. Neuroscience 37:767-773.

Thornton SR, Smith FL. 1997. Characterization of neonatal rat fentanyl tolerance and dependence. J Pharmacolo Exp Ther 281:514-521.

Thornton SR, Wang AF, Smith FL. 1997. Characterization of neonatal rat morphine tolerance and dependence. Eur J Pharmacol 340:161167.

Tremblay EC, Charton G. 1981. Anatomical correlates of morphinewithdrawal syndrome: differential participation of structures located within the limbic system and striatum. Neurosci Lett 23:137-142.
Wei ET. 1981. Enkephalin analogs and physical dependence. J Pharmacolo Exp Ther 216:12-18.

Wei E, Loh HH, Way EL. 1973. Brain sites of precipitated abstinence in morphine-dependent rats. J Pharmacolo Exp Ther 185: $108-115$.

Windh RT, Little PJ, Kuhn CM. 1995. The ontogeny of mu opiate tolerance and dependence in the rat: antinociceptive and biochemical studies. J Pharmacol Exp Ther 273:1361-1374.

Zhu H, Barr GA. 2000a. Age dependent blockade of development of morphine dependence by MK-801 in the infant rat. Soc Neurosci Abstr 26 (in press).

Zhu H, Barr GA. 2000b. Naltrexone precipitated morphine withdrawal in infant rat is attenuated by acute administration of NOS inhibitors but not NMDA receptor antagonists. Psychopharmacology 150:325-336. 